\title{
El Movimiento Estudiantil Nicaragüense y la influencia de la Revolución Cubana
}

Public policies in Latin America, centralization against the proposal of decentralization, autonomy and its national formations.

Luis Manuel Andino Paiz

Licenciado en Diplomacia y Ciencias Políticas

Universidad Nacional Autónoma de Nicaragua, Managua

https://orcid.org/0000-0003-0493-9077

managua.luisma@gmail.com
Recibido: 10-01-2019

Aceptado: 10-03-2019

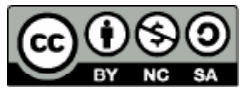

\section{Resumen}

El presente trabajo tiene como finalidad realizar un breve análisis del comportamiento político del Movimiento Estudiantil Universitario Nicaragüense y la influencia que en él ejerció la Revolución Cubana, ya que es de importancia estratégica el conocimiento de la historia para todos los estudiantes y principalmente para quienes ejercen cargos de representación en sus respectivas instituciones. La historia, entre otras cosas, sirve para conocer los esfuerzos que hicieron quienes nos precedieron, por dejarnos una sociedad donde se respete la dignidad del ser humano; porque solo conociendo objetivamente nuestra historia podremos empezar a valorar, querer e identificarnos con las herramientas necesarias y la rica herencia de nuestros antecesores. También se analizará el desarrollo del proceso revolucionario que Nicaragua vivió, debido a que la revolución nace del movimiento estudiantil, o por lo menos es allí donde más se activó el antagonismo a la dictadura de los Somoza y posterior defensa de la Revolución Popular Sandinista.

Palabras claves: Estudiantes, movimiento estudiantil, revolución cubana, revolución sandinista

\section{Abstract}

The purpose of this paper is to make a brief analysis of the political behavior of the Nicaraguan University Student Movement and the influence that the Cuban Revolution exerted on it, since knowledge of history is of strategic importance for all students and mainly for those who hold positions of representation in their respective institutions. History, among other things, serves to know the efforts made by those who preceded us, to leave us a society where the dignity of the human being is respected; because only knowing objectively our history can we begin to value, love and identify with the necessary tools and the rich heritage of our ancestors. It will also analyze the development of the revolutionary process that Nicaragua lived, because the revolution was born from the student movement, or at least that is where the antagonism to the Somoza dictatorship and subsequent defense of the Sandinista Popular Revolution was activated.

\section{Introducción}

La Revolución Cubana es una de las revoluciones que más ha tenido influencia en los movimientos sociales y políticos de América Latina, ha sido ejemplo de lucha, resistencia y dignidad, además de lograr derrocar una dictadura e instaurar en Latinoamérica un nuevo modelo de gobierno, cambiando las bases sociales y económicas existentes hasta 1959 , devolvió a la sociedad el derecho a la salud y la educación de manera gratuita, consolidándose como uno de los países con los índices más bajos en cuanto a la erradicación del analfabetismo y posicionándose como uno de los países pioneros en avances médicos, también logró constituir un sentimiento que identificó a la mayoría de pueblos latinoamericanos históricamente oprimi- 
dos, el antiimperialismo, vino a convencer a toda la sociedad que ante un pueblo insurrecto y decidido no hay armamento militar que lo detenga.

Además, de todos estos hechos, la Revolución Cubana impregna de sentimientos de identidad nacional, al ser la última de las colonias españolas en independizarse, quitando de esta manera el poder del que se había adueñado la burguesía de la época, quienes se pronunciaban al lado de los opresores para continuar con sus comodidades aún a costa de la explotación de la mayoría de la población.

Como respuesta a estas ideas y los avances alcanzados por la Revolución en Cuba, se implementó en este país un bloqueo criminal, llenando aún más de coraje y resistencia al pueblo cubano, estos y más elementos vienen a calar posteriormente en las ideas de los nacientes movimientos sociales en América Latina, y principalmente en Nicaragua, donde se desarrolló empatía y profun-

da amistad entre estos pueblos hermanos, quienes se identifican profundamente por su historia de lucha y resistencia.

El movimiento estudiantil nicaragüense se identifica con la revolución cubana cuando los jóvenes estudiantes tomaron la punta de lanza ante las injusticias y la opresión que se venía cometiendo con la sociedad de la época.

\section{Primeros indicios de la influencia de la Revolución cubana en el movimiento es- tudiantil nicaragüense}

El actuar universitario ha sido el pilar de la conformación de un movimiento estudiantil de decisivos y muy contradictorios cambios que se profundizaron a partir de 1979, pero para comprender mejor estos cambios se hace necesario hacer un análisis retrospectivo a los años de 1958, en donde la universidad se convirtió en un patrimonio social por su autonomía que hoy en día es insustituible, es publica en sus fines y en su matrícula, por lo cual se ha asumido un papel de incidencia en el quehacer científico, cultural y en diferentes aspectos de la vida cotidiana de la sociedad en general.

Es a partir de la Revolución cubana del año 1959 que se ven los primeros indicios de la influencia de este acontecimiento en el movimiento estudiantil de Nicaragua, por medio de la adopción de ideales socialistas e ideas de equidad y bien común, donde primaba lo social y lo colectivo, posteriormente se inicia un proceso unitario, idealista revolucionario, antiimperialista, bajo la conducción del pensamiento de Mariano Fiallos Gil, de una universidad con responsabilidad social donde se trabaja para salir del letargo intelectual y social, se busca la manera de construir una conciencia colectiva con justicia social y es en este momento donde el movimiento estudiantil alcanzó su mayor nivel de fuerza, prestigio, organización y movilización. Sus dirigentes se convirtieron en centros de opinión de gran importancia en la vida política del país y el estudiantado adquirió plena conciencia de la realidad del país y de América Latina, y sobre todo de la necesidad de un cambio radical de las estructuras económico-sociales del país como única salida válida a la problemática nacional.

Las bases ideológicas de ambas revoluciones fueron de corte Marxista-Leninista, de ahí surge la constante preocupación por la desigualdad entre los pueblos integrantes de un mismo territorio, sin embargo, estas revoluciones incorporaron la experiencia de lucha de sus propios países para construir y proponer sus propios modelos políticos ideológicos. En el caso cubano, los revolucionarios que después se les conocería con el nombre de Movimiento Revolucionario 26 de Julio, se reconocían como martianos, es decir que su referencia fue el ideario de José Martí. En Nicaragua, de igual modo, se rescató la gesta heroica y el pensamiento del General Augusto Nicolás Calderón Sandino y de allí devino la denominación de Frente Sandinista de Liberación Nacional (FSLN). (Revoluciones Cuba-Nicaragua 20 años después, 2008)

Ambos pensadores aportan a los universitarios de la época las ideas y lineamientos, la cual será la base fundamental para el posterior desarrollo de la lucha en la cual se enmarcó el movimiento estudiantil en 
sus orígenes y que al mismo tiempo logra mantener en la memoria de las nuevas generaciones.

Los jóvenes han impulsado una universidad que tiene la misión de dar respuestas a los problemas sociales del país, así como formar profesionales y técnicos con una actitud humanista y de estar en permanente proyección social en el marco de la equidad, solidaridad y justicia social, donde el movimiento estudiantil universitario juega un papel fundamental en generar alternativas nuevas basadas en el estudio de la historia de nuestros antepasados y en los fenómenos sociales de nuestro tiempo.

Es por lo anteriormente señalado, que este tema es de vital relevancia para la juventud y las personas que de una $\mathrm{u}$ otra manera se encuentran vinculados o se identifican con el movimiento estudiantil de las diferentes épocas, ya que sea en cualesquiera de los periodos históricos que ha vivido el movimiento estudiantil, ha llenado de vivencias, aprendizajes y experiencias a todas las generaciones, es innegable el poder de la participación de la juventud de manera decidida y organizada.

Para continuar con el abordaje de esta temática es importante destacar y tener en cuenta los conceptos fundamentales a analizar en este trabajo, para hablar de Movimiento Estudiantil primero hay que definir que es Movimiento Social, y porque es importante dentro de tantas temáticas propias de cada sociedad hablar precisamente de ello; según el autor Rafael Echeverría define el Movimiento Social como: "Comportamiento colectivo no institucional expresivo de un conglomerado social, orientado con cierta estabilidad a promover o resistir determinadas transformaciones en el sistema social global del que forma parte". (Echeverria, El concepto de Movimiento Social, 1994, pág. 130)

Con esta conceptualización de Movimiento Social podemos decir que el Movimiento Estudiantil es una agrupación colectiva de estudiantes que surge, por diferentes y específicas necesidades, en un determinado contexto que fue propicio y favorable que lo determinó de manera sustantiva la influencia del acontecer político inmediato, para llevar a cabo transformaciones y reivindicaciones sociales, integrada en la actualidad con una juventud, con una visión amplia y muchos deseos de llevar a cabo cambios que beneficien a toda la población, fundamentado en sus orígenes revolucionarios. Es importante definir con claridad entonces que el Movimiento Estudiantil se denomina también como expresión política organizada en una amplia variedad de demandas, pliegos petitorios, manifestaciones públicas, actos de apoyo o de repudio en contra o, a favor de distintos sistemas, este movimiento se ve alcanzado por los conflictos sociales que afectan el desarrollo de la sociedad, principalmente, cuando se ha intentado retroceder en los derechos conquistados a causa de conflictos ideológicos o por cambios en el sistema de gobierno.

Hay que tomar en cuenta que los primeros movimientos estudiantiles documentados con este carácter predominante, ocurren en Europa y en general se pueden dividir, por su causa en dos, aquellos que se inspiran en la mejoría de las condiciones del estudiantado en general, que son la futura generación intelectual de la sociedad y aquellos que son una respuesta a las condiciones de injusticia social que prevalecen al momento del movimiento, justificándose como un acto de justicia idealista.

Lewis S. Feuer, en su obra; El cuestionamiento estudiantil del establishment, en los países capitalistas y socialistas, dice: Los movimientos estudiantiles europeos constituyen así un espectro de difracción de los factores constitutivos de la estabilidad de sus respectivas sociedades. (Feuer, 1969, págs. 72-73)

Desde el término citado por Feuer, los movimientos estudiantiles surgen por sus propias necesidades, en un contexto social favorable que determina el acontecer social, pero que, también no están exentos al surgimiento de reacciones violentas contra esta expresión estudiantil organizada, pudiendo llegar al uso de la fuerza en su máxima expresión, situación que lastimosamente quedó evidenciada un 23 de julio de 1959 en la ciudad de León, con la masacre estudiantil.

El triunfo de la Revolución Cubana en enero de 1959 impulso en todos los pueblos de América Latina y el Caribe, particularmente en la juventud universitaria nicaragüense el espíritu antiimperialista, nacionalista y revolucionario del General de Hombre y Mujeres Libres Augusto C Sandino. Este acontecimiento del pueblo cubano, señaló el camino libertario para los incipientes revolucionarios nicaragüenses que padecían la dictadu- 
ra opresora de Somoza, el hecho que los jóvenes cubanos entre los que destacaban Fidel Castro y Ernesto el "Che" Guevara expulsaran de su pequeño país a una de las dictaduras más sanguinarias del continente y se enfrentaran y desafiaran a la súper potencia imperial yanqui a poca distancia de sus costas (90 Millas), hiso que la juventud soñara en realizar esa gesta heroica en nuestro país.

Entre los jóvenes universitarios que mejor percibieron el mensaje de la Revolución Cubana se encontraba el estudiante de la carrera de derecho Carlos Fonseca Amador, miembro de la directiva del Centro Universitario de la Universidad Nacional (CUUN), como secretario de relaciones, el cual convirtió en una de sus principales banderas de agitación, la búsqueda de la libertad de los pueblos oprimidos por la dictadura de los Somoza. En 1959 Carlos es seleccionado para pronunciar el discurso de inicio del año académico y el primer año de aniversario de la autonomía universitaria, posteriormente organizaría asambleas estudiantiles demandando la libertad de profe-
La influencia de la revolución cubana a los procesos sociopolíticos de América Latina y el Caribe es innegable, principalmente en lo que respecta a la ideología de izquierda, al deseo de la igualdad social, justicia y participación de manera equitativa e igualitaria, timiento de simpatía hacia el proceso cubano existente en las filas universitarias y lo tradujo en una intensa labor de propaganda, agitación, movilización y organización que lo llevó a convertirse en la fuerza de vanguardia del pueblo por medio de su brazo armado el Frente Estudiantil Revolucionario (FER), y posterior la Fundación del Frente Sandinista de Liberación Nacional (FSLN) fundado por estudiantes Universitarios de manera inicial como Movimiento de Liberación Nacional Nueva Nicaragua.

El ideario de Sandino se va manifestando entonces desde las aulas de clases y pasillos de la universidad en discursos, panfletos y pintas inicialmente, hasta que el estudiante universitario Carlos Fonseca Amador Propone a los miembros del MLNN entre ellos Tomas Borge, Silvio Mayorga, Faustino Ruiz y Santos López el nombre de Frente Sandinista de Liberación Nacional para la lucha armada como único camino de liberación.

Ante estos acontecimientos el sores y estudiantes detenidos por actividades subversivas contra la dictadura, organiza el primer grupo juvenil para independizarse políticamente, realizando distintas actividades y manifestaciones en contra de la tiranía.

En junio del mismo año Carlos Fonseca se organiza y se integra en la columna guerrillera Rigoberto López Pérez, ocurriendo una masacre en el Chaparral, en la frontera de Honduras, este es herido de bala en el pulmón, acontecimiento que provoca que en el festival de los pelones que se realiza en el mes de julio del mismo año, los estudiantes se movilicen exigiendo libertad para los heridos y detenidos, esta masacre del 23 de julio de 1959, da inicio a un proceso de profundos cambios políticos, resultando posteriormente la creación del FSLN el 23 de Julio de 1961.

La revolución cubana en nuestro país alimentó el clima nacionalista y antiimperialista y la beligerancia que imperaban en el movimiento estudiantil de los años 60 y contribuyó a definir posiciones dentro de la universidad; en un principio fue el Centro Universitario de la Universidad Nacional (CUUN) quien mejor canalizó este sen- propio imperialismo yanqui se vio obligado a desarrollar medidas de contención, como el caso del programa de la "Alianza para el Progreso" que en Nicaragua se materializa en una especie de entrega de parcelas en Zelaya Central en lo que hoy se conoce como Nueva Guinea.

Estas acciones abonaron a la resistencia y el sentimiento nacionalista, los ideales libertarios y de lucha, en contra de la opresión y los asesinatos constantes de todos aquellos que manifestaran su inconformidad ante los hechos y el entreguismo, intervencionismo, y demás actos que Somoza cometía a favor de Estados Unidos y en contra del pueblo nicaragüense.

En su "batalla de las ideas "expresión utilizada por el gobierno Cubano durante la lucha convocada para lograr el regreso del niño Elían González al seno de su padre, se hace el llamado a lograr la transformación desde donde se pueden lograr las transformaciones más profundas y donde de alguna manera se encuentran la raíz de los problemas y al mismo tiempo la solución a los mismos.

Esta expresión juvenil organizada debe luchar por que 
el acceso a la educación universitaria en la región continúe por el camino vigente y mantenga esos derechos conquistados, a poco más de un año de haberse celebrado el centenario de la reforma de córdoba, movimiento que significó la democratización de la educación superior y fue la antesala de otros procesos como el cogobierno que culminó con una universidad abierta al pueblo y de acceso gratuita, no ha sido un derecho adquirido en todos los países de la región, esa es la nueva lucha que se debe conquistar, ya que en cambio se han manifestado grandes desigualdades entre las naciones americanas. En este sentido Ezequiel Nino afirma:

"América Latina ha puesto el énfasis en la educación primaria y probablemente ha descuidado también que se puede mejorar la igualdad de oportunidades concentrando energías y recursos debidamente focalizados en la educación superior. En relación al PIB de cada país, el presupuesto destinado a educación superior es el más bajo en relaciona a los países de la OCDE las excepciones son Bolivia y cuba". (Ezequiel, 2011, pág. 357)

Ante este hecho habría que agregar, de acuerdo a la perspectiva personal, a Nicaragua y Venezuela que por supuesto es mucho mayor, siendo estos juntos a Cuba, Argentina y Bolivia de los pocos países de la región que aun conviven con el sistema de educación superior gratuito y de ingreso irrestricto, a como se ha venido luchando en la región de América Latina desde 1959 año en que se daría la Revolución Cubana.

La influencia de la revolución cubana a los procesos sociopolíticos de América Latina y el Caribe es innegable, principalmente en lo que respecta a la ideología de izquierda, al deseo de la igualdad social, justicia y participación de manera equitativa e igualitaria, esta influencia es más evidente en nuestro país ya que por aquellos años, poco después del triunfo revolucionario fueron muchos los cuadros jóvenes que viajaron a Cuba a recibir preparación en lo ideológico, político y militar, cultural y académica, es imposible hablar de Cuba y no destacar su enorme labor en cuanto a las mejoras al sistema de salud y su modelo educativo a todos los niveles, el pueblo cubano es un pueblo culto, el analfabetismo ha sido reducido a grandes escalas, dejándolo en niveles mínimos, por no decir nulos, esta gran labor ha sido evidente no solo en este país, sino, también, en el nuestro con la participación masiva de voluntarios cubanos se convirtieron en los asesores del sistema educativo para así, parte de la población nicaragüense, la juventud profesional de la época emprendiera la gran Cruzada Nacional de Alfabetización

La legitimidad de la lucha en que se gestaron ambas revoluciones fue el respaldo que permitió realizar profundas reformas sociales que favorecieron a los sectores más desposeídos de la sociedad, campañas de alfabetización, gratuidad en la atención médica, extensión de la seguridad social a toda la población, reformas agrarias, así mismo se resalta la importancia de la participación de todos los segmentos sociales siendo estos los principales protagonistas, con un papel de gestores de todos los procesos.

\section{Conclusión}

Son los estudiantes y la juventud en general quienes toman la vanguardia y la lucha ante los procesos de colonialismo y represión que persistían en tiempos anteriores. Con el triunfo revolucionario tanto del pueblo cubano como el nicaragüense se logra mandar un mensaje emancipador al imperio estadounidense, los pueblos conscientes de su historia y de su papel dentro de la sociedad logran consolidar los primeros esfuerzos que realizaran los personajes que más destacan dentro de ambas revoluciones, Martí y Sandino son el referente que tomarían después grandes personajes de la historia nicaragüense y cubana.

Por tal razón, es ineludible destacar que el origen social de los dirigentes y militantes de estos movimientos que posteriormente se conformaron, fue integrado por capas medias urbanas, razón por la cual se logra percibir la influencia en las universidades propiamente, segmento que se encargó del estudio del pensamiento de José Martí y el de Augusto C. Sandino, personajes que han inspirado ideales de libertad, igualdad y justicia que hasta el día de hoy prevalecen en la historia y 
sobre todo en las páginas de un movimiento estudiantil a la vanguardia de los procesos sociales, y siempre preocupado porque se mantengan esos derechos que han costado sangre a grandes héroes de ambas naciones, la similitud en los orígenes y desarrollo del proceso hacen que se identifique este movimiento estudiantil y mantenga su anhelo de construir una patria mejor para todos y que las generaciones futuras puedan contar con esas garantías con las cuales hoy jóvenes cuentan, para mejorar sus vidas y las de sus familias, consolidando juntos un proyecto social impulsado desde hace ya varias décadas.

El movimiento estudiantil tiene en sus brazos la responsabilidad de velar por los derechos y garantías del pueblo, así como mantener viva la memoria histórica en la comunidad universitaria de todos esos héroes y mártires que ofrendaron su vida en defensa de estos derechos

\section{Bibliografía}

Echeverria, R. (1974). Seminario Latinoamericano: hacia una conceptualizacion del fenomeno de los movimientos universitarios de America Latina. Santiago de Chile: Patricio Dooner.

Echeverria, R. (1994). El concepto de Movimiento Social. Patricio Dooner.

Ezequiel, N. (2011). La desigualdad en el acceso de la educacion univeristaria Argentina. Lecciones y Ensayos \#89, 357.

Feuer, L. (1969). El cuestionamiento estudiantil del establishment en los paises capitalistas y socialistas. Buenos Aires: Paidos.

Gaona, H. T. (1998). Cultura política, poder y racionalidad. Alteridades, 8, 157.

Revoluciones Cuba-Nicaragua 20 años después. (30 de Diciembre de 2008). El Nuevo Diario.

\section{Luis Manuel Andino Paiz}

Licenciado en Diplomacia y Ciencias Políticas, Estudiante activo de la carrera de Derecho, estudiante de la tercera cohorte de la Maestría de Antropología y liderazgo social en la UNAN-Managua, Presidente Nacional del Ejecutivo de la Unión Nacional de Estudiantes de Nicaragua (UNEN), poseedor de la orden independencia cultural Rubén Darío otorgada por el Presidente de la Republica, ha trabajado en diferentes espacios de Liderazgo estudiantil, ha sido miembro del Consejo Superior de Universidades de Centroamérica y el Caribe (CSUCA), fue presidente de la Federación de Estudiantes de Centroamérica y el Caribe (FEUCA), ex miembro del Consejo Universitario de la UNAN-Managua, actualmente miembro pleno del Consejo Nacional de Universidades (CNU), del Secretariado General de la Organización Continental Latinoamericana y Caribeña de Estudiantes (OCLAE), participó en distintos congresos y encuentros estudiantiles entre los más relevantes: Encuentro Mundial de la Juventud y los Estudiantes en Sochi, Rusia. Participante activo en temas de gestión y políticas públicas, miembro titular de la Mesa de negociación en el contexto de la crisis sociopolítico generado por el intento fallido de Golpe de Estado en Nicaragua. 